\title{
Antecedentes históricos de la potestad sancionadora de la Administración en Chile ${ }^{* * * * * *}$
}

\section{Historical background of the sanctioning power of the Administration in Chile}

RESUMEN

Este trabajo tiene por objeto dar cuenta del origen y desarrollo de la potestad sancionadora de la Administración en Chile. La hipótesis central de esta investigación postula que su origen se encuentra en la actividad de policía que llegó a América por aplicación del derecho castellano-indiano, a partir de la cual fue evolucionando hasta su consolidación actual como una potestad más de la Administración.

PALABRAS CLAVE

Derecho administrativo sancionador, actividad de policía, tolerancia constitucional, ius puniendi.

\section{ABSTRACT}

The purpose of this work is to account for the origin and development of the sanctioning authority of the Administration in Chile. The central hypoth-

Doctora en Derecho. Investigadora y profesora de Derecho Administrativo de la Pontificia Universidad Católica de Valparaíso (Valparaíso, Chile).Contacto: f.gomez.g@pucv.cl ORCID ID: 0000-0003-4769-6749.

** Recibido el 1..$^{\circ}$ de mayo de 2018, aprobado el 11 de junio de 2019.

Para citar el artículo: GómEz GonzÁLEZ, R. F. Antecedentes históricos de la potestad sancionadora de la Administración en Chile. En Revista Derecho del Estado, Universidad Externado de Colombia. N. ${ }^{\circ} 44$, septiembre-diciembre de 2019, pp. 361-384.

DOI: https://doi.org/10.18601/01229893.n44.13

*** Esta investigación se enmarca dentro del Proyecto FONDECYT Postdoctoral n. ${ }^{\circ} 3190494$ "Sanciones administrativas y derechos fundamentales. Análisis de temas específicos a partir de los principios, garantías y derechos regulados en la Constitución". Asimismo, en la realización de este trabajo se contó con el apoyo del proyecto FONDECYT Regular n. ${ }^{\circ} 1161741$ "Análisis y revisión dogmática del derecho administrativo sancionador en Chile a partir de su parte especial".

También, la investigación cuenta con el apoyo del proyecto de investigación "Derecho Administrativo Sancionador 2.0" (2018-RTI-096688-B-100), Proyecto I+D+i "Retos Investigación" 2018, del Ministerio de Ciencia, Innovación y Universidades de España y del Fondo Europeo de Desarrollo Regional (FEDER). 
esis of this research postulates that its origin is found in the police activity that came to America through the application of Castilian-Indian law, from which it evolved until its current consolidation as another authority of the Administration.

KEYWORDS

Administrative Law Sanctioning, Administrative Police, Constitutional Tolerance, Ius Puniendi.

SUMARIO

Introducción. 1. La policía y la potestad sancionadora en Chile. 1.1. Antecedentes de la potestad sancionadora en Chile. 1.2. La expansión del poder de policía luego de la declaración de Independencia. 1.3. Las sanciones administrativas y su origen en el poder de policía. 2. Las sanciones administrativas en el Código Penal de 1874.3. La necesidad de un régimen sancionador racionalizado. 3.1. La evolución de la legislación administrativa sancionadora. 3.2. Las reacciones dogmáticas. 3.3. Los pronunciamientos de la jurisprudencia judicial en torno al poder sancionador de la Administración. 3.4. El punto de inflexión impuesto por la sentencia Rol n. ${ }^{\circ} 244$ del Tribunal Constitucional. 3.5. Análisis de los recientes cuestionamientos a la constitucionalidad de la potestad sancionadora: los casos Código de Aguas y Servicio Nacional del Consumidor (SERNAC). Balance final. Referencias.

\section{INTRODUCCIÓN}

La construcción del derecho administrativo sancionador en Chile se ha realizado a partir de una serie de interpretaciones jurisprudenciales y aportes doctrinales; sin embargo, aun quedan por resolver algunas de sus problemáticas, derivadas fundamentalmente de la ausencia de una regulación general que supla los vacíos normativos existentes en las regulaciones sectoriales.

Para comprender el estado actual de la potestad sancionadora es necesario efectuar una revisión de sus orígenes. La lógica de algunas disposiciones e instituciones solo puede ser entendida a la luz de su concepción, de su evolución y de los ajustes que han recibido en su proceso de formación. Asimismo, la revisión de sus bases históricas permitirá comprender el cambio que ha sufrido la potestad, desde una actividad moderada y sin mayor profusión, hasta una actividad extendida y vigorosa, esencial para el funcionamiento de la Administración.

De esta manera se demostrará, por una parte, que el origen de la potestad sancionadora se encuentran en el poder de policía, y por la otra, que la potestad ha sido objeto de una serie de ajustes, los cuales principalmente han buscado 
adecuar sus disposiciones a los principios constitucionales y a las garantías y derechos fundamentales de los particulares, mostrándose en la actualidad como una potestad más racionalizada, establecida como una herramienta necesaria para que la Administración cumpla con sus fines de interés general.

\section{LA POLICÍA Y LA POTESTAD SANCIONADORA EN CHILE}

\subsection{Antecedentes de la potestad sancionadora en Chile}

Luego de la Independencia se estableció que el ejercicio de la potestad penal debía ser legalizado y judicializado, de manera que la facultad de juzgar las causas criminales quedaría radicada en los tribunales ${ }^{1}$. Al margen del sistema penal quedaron las medidas aplicadas por la Administración como respuesta a ciertos atentados al orden y la seguridad públicos, atribuciones que, en su mayoría, provenían del Antiguo Régimen ${ }^{2}$ y que fueron mantenidas como manifestaciones de la actividad de policía ${ }^{3}$.

La pervivencia del poder de policía, comprensivo de un conjunto de medidas coactivas atribuidas a la Administración para garantizar que los particulares ajusten su actividad a los fines de interés general que persigue, responde a la necesidad de mantener el orden público y la seguridad pública luego de la proclamación de la Independencia ${ }^{4}$. En efecto, si bien los súbditos pasaron a ostentar un conjunto de derechos que podían ejercer libremente, sin que mediara una autorización previa del Estado, tales derechos no eran absolutos puesto que no podían poner en riesgo el orden público establecido ${ }^{5}$, y la potestad de policía se mostró como el instrumento idóneo para evitar

1 Si bien en la Constitución de 1818 la referencia no era del todo clara, la Carta de 1823 se encarga de hacer una mención expresa en su artículo 199.

2 La policía fue incorporada al ordenamiento jurídico chileno a través de diversas disposiciones del derecho castellano-indiano, el cual ha sido descrito como un derecho marcado por el intervencionismo y el dirigismo estatal. Véase, al respecto, GuzMán, A. Historia de la codificación civil en Iberoamérica. Navarra: Thomson-Aranzadi, 2006, 39 y 58.

3 Situar el origen de la potestad sancionadora en el poder de policía es lo que ha generado que cierta doctrina la caracterice como un resabio absolutista. Véase, en este sentido, Sото KLoss, E. Derecho administrativo penal. Notas para el estudio de la potestad sancionadora de la Administración. En Boletín de Investigaciones. N. ${ }^{\circ} 44-45,1979 / 1980,95-103$, nota 3. Entre tanto, para otros autores dicho origen daría cuenta de un derecho represivo pre-beccariano, esto es, de una potestad de carácter amplio, de autotutela, ajena a controles y desprovista de garantías para los infractores. Véase García de Enterría, E. y Fernández, T. R. Curso de derecho administrativo. 10. ${ }^{\text {a }}$ ed. Madrid: Thomson Civitas, 2006, II, 169.

4 VIÑUELA, M. Algunas reflexiones en torno al derecho administrativo sancionador: la aplicación residual de sanciones administrativas y el principio de legalidad de la penas. En Arancibia, J. y Alarcón, P. (coords.), Sanciones administrativas. Santiago: Thomson Reuters y La Ley, 2014, 115.

5 GARRIDO, F. Los medios de la policía y la teoría de las sanciones administrativas. En Revista de Administración Pública. N. ${ }^{\circ}$ 28, 1958, 11-12. 
los peligros que pudieran derivar de su ejercicio abusivo. En definitiva, mediante la policía se buscaba tutelar el orden público frente a eventuales perturbaciones que lo pudieran afectar.

Recordemos que la policía fue el título que por antonomasia justificó las intervenciones del Antiguo Régimen sobre los súbditos ${ }^{6}$. Luego de la Independencia, su ejercicio quedó entregado a las nuevas autoridades, las que debían calificar la concurrencia de los atentados a las normas de policía y determinar las medidas correspondientes conforme a procedimientos exiguos, desprovistos de las garantías sustantivas y procesales contenidas en la legislación penal ${ }^{7}$.

\subsection{La expansión del poder de policía luego de la declaración de Independencia}

La declaración de Independencia implicó una emancipación política ${ }^{8}$ mas no una autonomía jurídica ${ }^{9}$, por lo que la actividad de policía que se venía ejerciendo por el gobierno regio pasó a las manos de las autoridades del gobierno republicano ${ }^{10}$. De esta manera, el advenimiento de la era republicana

6 Al respecto cabe tener presente que "bajo el Estado absoluto los asuntos de policía constituían un ámbito separado del orden jurídico, donde la Administración llegó a gozar de un enorme espacio de libertad, pues las determinaciones que se adoptaran en esta materia eran inapelables. Así las cosas, el análisis de la cuestión no dejaba de ser irrelevante supuesta la delimitación entre asuntos jurídicos, sometidos a control judicial, y asuntos administrativos, propios de la policía". CORDERo, E. Derecho administrativo sancionador. Bases y principios en el derecho chileno. Santiago: Legal Publishing, 2014,73. Por su parte, para Flores, las sanciones administrativas corresponderían a la función de policía represiva, aludiendo a aquella actividad que busca la retribución abstracta de la conducta ilícita, es decir, que comprende un carácter reaccional, respecto de un comportamiento que se considera administrativamente ilícito. Véase FLORES, J. C. "Función fiscalizadora y potestad sancionadora de la Administración". En ARANCIBIA y Alarcón (coords.), Sanciones administrativas, cit., 272.

$7 \quad$ Si bien en la Constitución de 1818 se recogen las garantías a ser oído antes de la aplicación del castigo (art. $2^{\circ}$ ), a la presunción de inocencia (art. 3..$^{\circ}$ ), a la pronta administración de justicia (art. $6 .^{\circ}$ ), a la proscripción de la pena trascendental (art. 13), entre otras, es posible advertir que todas ellas fueron circunscritas a los ilícitos penales.

8 Que se tradujo en la adopción de una constitución política, en la determinación de la forma en que se organizaría el nuevo gobierno (modelo republicano liberal representativo) y en la emisión de leyes complementarias acordes al nuevo régimen político. Véase GuzMán. Historia de la codificación civil en Iberoamérica, cit., 56.

9 Por Decreto del 11 de enero de 1825, el Director Supremo Ramón Freire dispuso: "entre tanto se dictan las leyes que sirvan de base y organicen la República y su administración, obsérvese el orden actualmente existente". Boletín de las Leyes y Decretos del Gobierno, Libro II (1824-1825), 85.

10 En Hispanoamérica las revoluciones de independencia cumplieron en lo político el mismo papel que la Revolución Francesa en Europa, esto es, abolir el Antiguo Régimen monárquico absolutista. Sin embargo, a diferencia de lo ocurrido en aquella, no hubo cambios en el orden económico-social indiano, los cuales ni siquiera fueron considerados en el programa independentista. La consecuencia de ello fue que ciertas tradiciones del orden indiano, como el 
no suprimió los poderes de policía, sino que efectuó un ajuste de los mismos a la nueva estructura de gobierno.

En este punto cabe tener presente que en el momento de la ruptura del vínculo que existía con España el concepto de policía estaba, ante todo, referido a un poder genérico, amplio, indeterminado y expansivo, que no precisaba de mayores formalismos para imponer medidas restrictivas a los ciudadanos bajo la consigna prevencionista como título justificante ${ }^{11}$. Si bien se había intentando acotar su concepto a la seguridad y al orden público general, la policía también buscaba evitar los peligros que se pudieran generar por el ejercicio de actividades privadas lícitas objeto de control administrativo, lo que dio cabida a la distinción entre policía general y policías especiales ${ }^{12}$.

La existencia del poder de policía facilitó al naciente Estado, que buscaba asegurar su normal funcionamiento, el cumplimiento de los fines propios de sus primeras instituciones, lo cual se fue logrando a partir de una interpretación y reinterpretación de la actividad de policía originaria ${ }^{13}$.

derecho de policía, se traspasaron a los Estados sucesores, en los cuales su configuración como entidades autónomas no implicó ninguna mutación de dicho orden. Véase GuzMán. Historia de la codificación civil en Iberoamérica, cit., 57 ss. Corrobora el anterior aserto la circunstancia de que "[1]a policía de seguridad continuó con la aplicación de medidas punitivas sobre aquel sector de la población que no cumplía con las normativas aún vigentes del periodo colonial y/o con las incipientes leyes patrias que se fueron formulando durante los primeros años republicanos [...]. La legislación de la época de dominio hispano se mantuvo hasta bien adentrado el siglo XIX, como gran parte de la estructura estatal y social creada en esa etapa". RoJAs, M. y LEón, M. Control social y construcción de hegemonía en la ciudad de Concepción (Chile), 1860-1900. En Anuario de Estudios Americanos, Sevilla. 70, 2, 2013, 641-671. Ahora bien, las normas españolas también sirvieron de fundamento para el establecimiento de medidas de represión propias del nuevo Estado. Véase, al respecto, BocksANG, G. El "secuestro de bienes" como primera sanción administrativa del Estado de Chile. En AranciBia y Alarcón (coords.), Sanciones administrativas, cit., 635.

11 Santamaría, J. A. Principios de derecho administrativo general. Vol. II, 4. a ed. Madrid: Iustel, 2016, 292 ss.

$12 \mathrm{Al}$ igual que aconteció en el derecho comparado, el concepto de policía general fue objeto de una evolución, en donde ya no quedó circunscrito a asuntos de mera seguridad, sino que extendió su ámbito de actuación a ciertas materias específicas (minera, forestal, aguas, circulación, entre otras), lo cual se denominó policía especial. Este cambio tuvo su origen en la ampliación del concepto de orden público, conforme al cual nuevos aspectos de interés público venían a justificar el empleo de las típicas medidas de coacción de la policía. Véase GARRIDO, F.; Palomar, A. y Losada, H. Tratado de derecho administrativo. Parte general. Conclusión. Vol. II, 12. ${ }^{\text {a }}$ ed. Madrid: Tecnos, 2006, 169.

13 Sobre la supervivencia de la noción de policía en el Estado constitucional, véase SANTAMARÍA. Principios de derecho administrativo general. Vol. II, cit., 293 ss. 
Dicha potestad fue recogida expresamente en los primeros textos constitucionales ${ }^{14} \mathrm{y}$ en diversas regulaciones generales ${ }^{15} \mathrm{y}$ sectoriales ${ }^{16}$. Asimismo, tuvo un rol protagónico en la regulación local, toda vez que las diversas leyes sobre organización y atribuciones municipales ${ }^{17}$ otorgaron a los municipios variadas competencias de policía en materia de urbanismo, salubridad, aseo y ornato y de seguridad pública (urbana o rural), entre otras, las que podían ser reguladas mediante ordenanzas sujetas a ciertos máximos sancionadores ${ }^{18}$. Junto con ello, algunas disposiciones conferían a los alcaldes jurisdicción como jueces de policía municipal ${ }^{19}$.

Toda esta regulación da cuenta del significativo poder de las autoridades administrativas, y del hecho de que en un primer momento la policía estuvo circunscrita al orden y a la seguridad pública. Sin embargo, como se verá

14 Un recorrido por las normas constitucionales desde 1818 hasta 1833 demuestra que el concepto de policía fue trasladado del Estado absoluto al Estado republicano.

15 V.gr., el Reglamento de policía del 14 de abril de 1813; el decreto dictado por el Director Supremo Ramón Freire, con la firma de Mariano Egaña, el 21 de mayo de 1823, que estableció diversas disposiciones de policía; y la Ley de Régimen Interior del 10 de enero de 1844, que contemplaba diversas potestades de policía para intendentes y gobernadores.

16 Véase, al respecto, Letelier, V. Génesis del Estado y de sus instituciones fundamentales. Introducción al estudio del derecho público. Buenos Aires: Cabaut, 1917, 546-548, y ANGUITA, R. Leyes promulgadas en Chile. Desde 1801 hasta el 1. ${ }^{\circ}$ de junio de 1913. Santiago: Imprenta Litografía, 1913.

17 En general, las municipalidades eran competentes para conocer respecto de las policías de salubridad, seguridad y orden público, aseo, comodidad, ornato y recreo; urbana y rural; entre otras. De dichas competencias dan cuenta las leyes sobre organización y atribuciones de las municipalidades del 8 de noviembre de 1854 , del 12 de septiembre de 1887 y del 22 de diciembre de 1891, así como su texto refundido en el Decreto n. ${ }^{\circ} 281$ del 28 de enero de 1915.

18 Así, la Ley sobre Organización y Atribuciones de las Municipalidades del 8 de noviembre de 1854, en su artículo 107, indicaba: "Las multas o penas pecuniarias que en dichas ordenanzas se señalaren a las faltas, no podrán exceder de cuarenta pesos. Cuando el infractor no pudiere pagar la multa, sufrirá una prisión en proporción de un día por cada peso". Por su parte, el texto refundido de la Ley sobre Organización y Atribuciones de las Municipalidades del 22 de diciembre de 1891, en su artículo 27, señalaba: "Como encargadas de administrar los servicios locales, jeneral i especialmente indicados, i de hacer ejecutar sus resoluciones, corresponde a las Municipalidades: $1 .^{\circ}$ Imponer a las infracciones de las prescripciones municipales penas hasta de cuarenta pesos de multa en simples decretos o reglamentos, i desde cuarenta $\mathrm{i}$ uno hasta sesenta pesos, en ordenanzas; sin perjuicio, en todo caso, del comiso a que haya lugar de los objetos especificados en el artículo 499 del Código Penal".

$19 \mathrm{Al}$ respecto, la Ley sobre Organización y Atribuciones de las Municipalidades del 8 de noviembre de 1854, en su artículo 105, señalaba: "La jurisdicción de policía que en la cabecera del departamento corresponde a los alcaldes, será ejercida en las demás poblaciones del departamento, en la parte a que hubiere lugar, por los subdelegados e inspectores". Por su parte, su artículo 62 disponía: "Los fallos que pronunciaren los alcaldes, ejerciendo la jurisdicción de jueces de policía municipal, son apelables para ante la comisión de alcaldes, siempre que las multas que aplicaren excedan de doce pesos". En la actualidad, la función de policía local está radicada en un órgano de naturaleza jurisdiccional. 
a continuación, paulatinamente se fue extendiendo a un mayor número de autoridades y de materias ${ }^{20}$.

\subsection{Las sanciones administrativas y su origen en el poder de policía}

Dado el incremento de las funciones administrativas y el desarrollo social y económico que comenzó a experimentar el país, la policía se fue ampliando a cualquier tipología de "orden", caracterizado por un poder altamente centralizado $^{21}$. Así, desde la policía general, destinada a reprimir ilícitos y faltas bagatelarias o de menor cuantía, se transitó a una potestad más acorde con el sistema social, político y económico imperante, ampliándose a otras materias (policías especiales), además de establecer medidas cada vez más intensas, todo ello con el objeto de responder a las necesidades y finalidades propias de los nuevos tiempos.

La transformación que experimentó el poder de policía no estuvo exenta de críticas. Los principales cuestionamientos de su expansión dicen relación con el mantenimiento e incremento, en algunos casos, de las medidas de coacción; con su configuración bajo amplios márgenes de discrecionalidad, así como con las escasas garantías otorgadas al particular para su aplicación, lo que ciertamente era cuestionable atendidas las bases constitucionales de Estado de derecho. Es por ello que autores como Huneeus rechazaron la idea de que una persona pudiera ser castigada por una autoridad distinta a los tribunales de justicia, siendo la facultad de aplicar penas constitucionalmente exclusiva del poder judicial ${ }^{22}$.

No obstante dichos cuestionamientos, la función de policía se mantuvo en manos de la autoridad ejecutiva, si bien sujeta a una serie de ajustes: i) su

20 Por ejemplo, la Ley del 30 de diciembre de 1886, sobre Policía Sanitaria, y la Ordenanza General de Salubridad del 10 de enero de 1887; la Ordenanza de policía de 1873, de Curicó, la cual fijó los límites de la ciudad y estableció ciertas obligaciones y prohibiciones; y la Ordenanza sobre policía fluvial y de irrigación para el valle de Copiapó, de 1875, en particular en sus artículos 30 a 35; entre otras regulaciones.

$21 \mathrm{Al}$ respeto, Luis Cordero explica: "El problema de la concepción liberal es que fue superada ampliamente por la realidad, porque el Ejecutivo heredó y reconstruyó la organización burocrática desde el antiguo régimen, pero en un contexto de conceptualización de un Estado gendarme que no podía ir más allá que el 'orden público en el interior y la seguridad externa de la República' (el poder de policía[,] en la clásica nomenclatura), lo que llevó a sofisticar la maquinaria administrativa, ampliando la categoría del 'poder de policía' a cualquier tipología de orden, disponiendo además de un sistema altamente centralizado del Poder". Cordero, L. Lecciones de derecho administrativo. Santiago, Legal Publishing, 2015, 53-54, nota 155.

22 Huneeus, J. La Constitución ante el Congreso. Santiago: Cervantes, 1891, vol. 3, II, 230-231, 234, 238 y 326. Esto a propósito de lo dispuesto en los artículos 106 y 120 de la Ley de Régimen Interior de 1844, que permitía a los gobernadores imponer multas no superiores a 25 pesos o, en su defecto, prisión que no excediera de 48 horas, a los individuos que les desobedecieran o faltaren el respeto, así como a aquellos que turbaren el orden o el sosiego públicos, lo que, en opinión del autor, contravenía el artículo 108 de la Constitución de 1833. 
ejercicio debía ser excepcional; ii) debía respetar el principio de legalidad y iii) su aplicación debía estar orientada a la finalidad pública que buscaba garantizar.

Además, dada su vinculación con el Antiguo Régimen (de sesgo autoritario ${ }^{23}$, el tradicional concepto de policía se fue decantando a lo largo de nuestra historia, no solo experimentando una depuración en cuanto a su contenido y alcance, sino también pasando a servir de base para conformar otras categorías jurídicas, entre ellas lo que hoy se conoce como potestad administrativa sancionadora ${ }^{24}$. Como bien señala Nieto, "es incuestionable que las sanciones administrativas han constituido siempre una simple manifestación de la Policía, de tal manera que donde hay policía aparecen las sanciones y hasta puede afirmarse que las sanciones son el pilar sobre el que se asienta la Policía puesto que sin ellas no podría ser efectiva"25.

En definitiva, en Chile las sanciones administrativas tendrían su origen en el poder de policía, el cual, luego de una paulatina evolución, dio lugar a diversas formas de intervención administrativa, siendo una de ellas la potestad sancionadora ${ }^{26}$.

\section{LAS SANCIONES ADMINISTRATIVAS EN EL CÓDIGO PENAL DE 1874}

Un siguiente paso en este desarrollo histórico vendrá dado por el reconocimiento expreso de la potestad represiva de la Administración en el Código Penal de $1874^{[27]}$. Dicho cuerpo legal dispuso, en sus artículos 20 y 501, que

23 En un estado inicial del constitucionalismo, el desprestigio que adquirió la función de policía del Estado "arrastró consigo toda la potestad sancionadora de la Administración -lo cual derivó en que se reconociera el monopolio estatal de la represión en los tribunales de justicia-; es igualmente cierto que, con el paso de los años, hoy resulta ilusorio negar la existencia de una potestad sancionadora propia y específica de la Administración". ViÑUELA. Algunas reflexiones en torno al derecho administrativo sancionador, cit., 113.

24 Con todo, hay autores que aún utilizan el término como sinónimo de potestad sancionadora. Así, por ejemplo, Bermúdez utiliza el término "policía ambiental". Véase Bermúdez, J. Reglas para la imposición de las sanciones administrativas en materia ambiental. En ARANCIBIA y Alarcón (coords.), Sanciones administrativas, cit., 609-632.

25 Nieto, A. Derecho administrativo sancionador. 5. a ed. Madrid: Tecnos, 2012, 56.

26 Para Nieto, "es incuestionable que las sanciones administrativas han constituido siempre una simple manifestación de la Policía, de tal manera que donde hay policía aparecen las sanciones y hasta puede afirmarse que las sanciones son el pilar sobre el que se asienta la Policía puesto que sin ellas no podría ser efectiva". NiETo. Derecho administrativo sancionador . 5. a ed., cit., 56. Por su parte, la doctrina nacional señala que en Chile los poderes punitivos de la Administración son tan antiguos como lo es la propia Administración, siendo ellos parte esencial de la función de policía estatal, entendida esta como uno de los componentes básicos de la función administrativa del Estado. Véase RAJEvic, E. La sinuosa reserva legal de la potestad sancionadora y los privados que ejercen funciones públicas: navegando entre relaciones de sujeción especial y la contractualización. En ArAnCiBIA y Alarcón (coords.), Sanciones administrativas, cit., 110.

27 Estas disposiciones siguieron el modelo dispuesto en los artículos 22 y 505 del Código Penal español de 1848. El último de estos preceptos surgió bajo la vigencia de la Constitución 
la autoridad podría aplicar multas y demás correcciones a los administrados en uso de sus atribuciones gubernativas.

Las aludidas disposiciones implicaron un reconocimiento de las sanciones gubernativas (administrativas) en manos de los órganos públicos, las cuales no se consideraban penas y, por tanto, las conductas que las originaran tampoco serían consideradas delitos. Como consecuencia de lo anterior, no les serían aplicables a las sanciones gubernativas ni las normas ni los principios establecidos en el Código Penal. De esta manera, la Administración (central o municipal) podría establecer "penas" -sanciones gubernativas- en normas infralegales, mediante reglamentos generales o particulares u ordenanzas municipales ${ }^{28}$. Por último, las "penas" -sanciones gubernativas- establecidas vía infralegal no podrían ser mayores que las señaladas en el Libro Tercero del Código Penal, relativo a las faltas, salvo la existencia de leyes especiales, las cuales podrían establecer sanciones gubernativas más elevadas. De esta manera, los artículos 20 y 501 del Código Penal:

i. Pueden considerarse como el primer reconocimiento de las sanciones administrativas;

ii. Remiten a las sanciones gubernativas y disciplinarias a un bloque normativo de contenido administrativo, dejando su regulación a lo dispuesto por la autoridad, en las ordenanzas municipales o en los reglamentos, o por el legislador, en las leyes especiales, y

iii. Esta remisión al orden jurídico-administrativo deja entregado su conocimiento y determinación a los criterios dispuestos por la autoridad, los cuales en esa época eran ostensiblemente amplios, sin sujeción a las garantías y principios previstos en el Código Penal para los ilícitos penales ${ }^{29}$.

La primera de las mencionadas disposiciones ha generado posiciones divididas en la doctrina penal. Así, para algunos autores la norma contemplaría una expresa separación de sistemas y, por tanto, de principios y regímenes jurídicos, lo que justificaría, por ejemplo, la concurrencia conjunta de sanciones administrativas y penales, impuestas por órganos distinto ${ }^{30}$. En tanto,

de 1837 , texto de carácter liberal y progresista que se asentó sobre el principio de separación de poderes y que confió al poder judicial la competencia para imponer penas, salvo casos excepcionales. Véase Nieto, A. Derecho administrativo sancionador. 4. ${ }^{\text {a }}$ ed. Madrid: Tecnos, 2005, 62.

28 Cabe recordar que en aquel entonces los municipios tenían diversas competencias de policía, las que venían regulando a través de ordenanzas, las si bien podrían continuar regulando, pero ahora sujetas a un nuevo límite sancionatorio.

29 Al respecto, Luis Rodríguez indica: "La existencia de esta potestad sancionadora a cargo de la Administración determinó que, en la práctica, los principios del derecho penal liberal quedaran circunscritos a lo que en estricto rigor constituye el ordenamiento jurídico-penal. La sanción administrativa, en cambio, comenzó a ser aplicada sin el más mínimo resguardo de los derechos de las personas y la situación hizo crisis cuando este tipo de sanciones pasó a tener cuantías muy superiores a las de las penas". RODRíGUEZ, L. Bases para distinguir entre infracciones criminales y administrativas. En Revista de Derecho, Valparaíso. Vol. 11, 1987, 121.

30 Etcheberry, A.Derecho penal.Parte general.3. a ed. Santiago: Jurídica de Chile, 1998, II, 
para otros, las sanciones y las penas tendrían una naturaleza análoga, por lo que entre ellas existirían solo diferencias de magnitudes, debiendo estar sujetas a principios y garantías semejantes a las penales como mecanismo de defensa de los derechos de los particulares ${ }^{31}$.

Ahora bien, existen conductas que históricamente el legislador ha estimado delitos y que posteriormente ha enviado a sede administrativa ${ }^{32} \mathrm{o}$ viceversa; asimismo, algunas regulaciones sectoriales dan cuenta de sanciones administrativas significativamente más gravosas que las penales ${ }^{33}$, de modo que ninguna de las posiciones dogmáticas logra explicar satisfactoriamente el patrón normativo que ha adoptado el legislador para la determinación de los delitos e infracciones, quien en definitiva establece discrecionalmente su configuración, aunque sujeto a ciertos límites ${ }^{34}$.

En definitiva, y no obstante las restricciones que el propio Código Penal estableció para la configuración de las sanciones gubernativas y disciplinarias, permitió que el legislador pudiera, mediante leyes especiales, habilitar a la Administración para conocer e imponer sanciones sin sujeción a los límites allí dispuestos, lo que en la práctica generó que lo que pretendía ser una excepción se convirtiera en regla general ${ }^{35}$.

Así las cosas, las sanciones administrativas aumentaron de manera proporcional al incremento de las finalidades que debía atender la Administración, tornándose cada vez más frecuente su establecimiento en las diversas disposiciones especiales. En general, se trata de medidas que carecen de una densidad normativa suficiente, al conferir un amplio margen de decisión a la autoridad administrativa sin un aumento de garantías que le permitiera al particular equilibrar su ejercicio.

\section{LA NECESIDAD DE UN RÉGIMEN SANCIONADOR RACIONALIZADO}

El tema de la potestad sancionadora no fue objeto de particular interés sino hasta los primeros años de la década de 1980, cuando algunos autores co-

132-133; NovoA, E. Curso de derecho penal chileno. 3. a ed. Santiago: Jurídica de Chile, 2010, I, 39 y 40 .

31 CURY, E. Algunas reflexiones sobre la relación entre penas penales y administrativas. En Boletín de Investigaciones. N. ${ }^{\circ} 44$ y 45, 1979/1980, 86-94; RODRíGUEZ. Bases para distinguir entre infracciones criminales y administrativas, cit., 127; GARRIDO, M. Derecho penal. Parte general. 3. ${ }^{\text {a }}$ ed. Santiago: Jurídica de Chile, 2002, I, 85 y 86, y BALmaceda, G. Manual de derecho penal. Parte general. Santiago: Librotecnia, 2014, 40 y 41.

32 Por ejemplo, la colusión.

33 V.gr., multas de elevada cuantía, extinción de la personalidad jurídica o medidas privativas de libertad.

34 CORDERo. Derecho administrativo sancionador, cit., 113 ss.

35 Sobre el particular, Aróstica sostiene que las leyes especiales importarían un "quiebre del sistema" penal. Véase ArósticA, I. Algunos problemas del derecho administrativo penal. En Revista de Derecho, Universidad de Concepción. N. ${ }^{\circ}$ 182, 1987, 77. 
menzaron a cuestionar que la Administración pudiera imponer castigos al margen de un debido proceso ${ }^{36}$, conforme a exiguos marcos regulatorios, con precarios mecanismos de control, con diversos niveles de discrecionalidad y al margen de los principios que desde antaño se aseguraban para el ámbito penal, como la legalidad, la tipicidad, la culpabilidad, la responsabilidad personal y subjetiva, entre otros. En términos generales, dicho interés responde al incremento de las sanciones administrativas y al aumento de su contenido lesivo.

El poder punitivo de la Administración parecía no encajar con el marco normativo establecido por la Constitución de 1980 y, por el contrario, muchas de las regulaciones sancionadoras se mostraban en conflicto con alguno de sus preceptos ${ }^{37}$. En otros términos, la represión administrativa presentaba cierta contradicción con las bases esenciales del Estado constitucional de derecho, principalmente con los derechos subjetivos establecidos a favor de las personas, por lo que, para mantener su vigencia como potestad restrictiva de derechos, debía generar una cierta armonía con los derechos asegurados constitucionalmente.

Todas estas circunstancias hicieron que la potestad sancionadora comenzara un proceso de racionalización, fundamentalmente a través de la jurisprudencia constitucional, seguida de pronunciamientos judiciales y administrativos y de una regulación sancionadora cada vez más conforme con la Constitución.

\subsection{La evolución de la legislación administrativa sancionadora}

A comienzos de la década de 1980 la legislación chilena contaba con una gran cantidad de leyes de diverso contenido sancionador, sin que ello significara necesariamente una debida correspondencia con la estructura constitucional existente y con los principios y derechos en ella contemplados. Este incremento normativo fue denominado por la doctrina nacional como "hiperinflación" o "elefantiasis" de las facultades represivas de los órganos públicos ${ }^{38}$.

36 Sото KLoss. Derecho administrativo penal, cit., 95-103. En esta publicación el autor sostuvo que de admitirse la constitucionalidad de la potestad sancionadora esta debiera estar sometida a un debido proceso, a un justo y racional procedimiento, y a una ejecución con declaración previa de constitucionalidad y legalidad efectuada por el juez (p. 101).

37 Como el instituto del solve et repete, establecido en diversas disposiciones sancionatorias como requisito previo para impugnar judicialmente una sanción administrativa. Véase Sото KLoss, E. Solve et repete. Notas sobre un resabio absolutista en el Estado constitucional del derecho. En Ius Publicum. Vol. 4, n. ${ }^{\circ}$ 6, 2001, 79-100, y ArAYA, M. El solve et repete frente al derecho administrativo sancionador. Un examen de legitimidad. En Revista de Derecho. N. ${ }^{\circ}$ 3, 2013, 95-126.

38 Aróstica. Algunos problemas del derecho administrativo penal, cit., 71, y Román, C. El castigo en el derecho administrativo. En Revista de Derecho y Humanidades. Vol. 1, n. ${ }^{\circ} 16$, 2010, 157. 
Para esa época, las facultades represivas de la autoridad se caracterizaban por su precaria densidad normativa, traducida en una deficiente regulación legal que implicaba: la configuración de tipos infraccionales desmesuradamente abiertos o bajo supuestos de responsabilidad objetiva; la falta de criterios para la determinación de sanciones; la omisión de normas sobre prescripción; el establecimiento de ilícitos con infracción al non bis in idem; la creación de presunciones de culpabilidad que podían afectar la presunción de inocencia; la ausencia de un procedimiento sancionatorio; entre otros ${ }^{39}$.

De esta manera, resultaba contradictorio que, mientras se propugnaba el respecto por los derechos y garantías de los particulares, tanto en sus relaciones verticales como horizontales, se vinieran estableciendo, vía legal o infralegal, atribuciones sancionadoras cada vez más reñidas con la Constitución.

En definitiva, la excepción contemplada en el artículo 501 del Código Penal se transformó en regla general, cuestión que tuvo como principal consecuencia la construcción, en paralelo, de un sistema represivo diverso al penal, disperso y heterogéneo, al margen de los notables desarrollos alcanzados por aquel en materia de garantías y principios ${ }^{40}$.

Sin perjuicio de que la existencia de una regulación sancionatoria general y de base aparece como una idea cada vez más distante ${ }^{41}$, en el último tiempo el legislador, alentado fundamentalmente por las precisiones provenientes de la jurisprudencia, ha configurando las disposiciones sancionadoras sectoriales disponiendo con un mayor detalle las conductas constitutivas de infracciones, su clasificación, los tipos de sanciones y los criterios que deben ser utilizados para su determinación, lo cual refleja un mayor grado de correspondencia con los principios constitucionales y con las garantías y derechos fundamentales de los particulares ${ }^{42}$.

39 CoRDERo. Derecho administrativo sancionador, cit., 130.

40 GARCía de ENTERRía, E. El problema jurídico de las sanciones administrativas. En Revista Española de Derecho Administrativo. N. ${ }^{\circ} 10,1976,409$. En igual sentido, SANTAMARía, J. A. y PARejo, L. Derecho administrativo. La jurisprudencia del Tribunal Supremo. Madrid: Centro de Estudios Ramón Areces, 1992, 198.

41 Si bien en el año 2004, a través del Boletín n. ${ }^{\circ}$ 3475-06, se presentó un proyecto de ley que buscaba establecer las bases de los procedimientos administrativos sancionatorios, dicho proyecto se archivó en su primer trámite constitucional, sin que hasta la fecha exista otra iniciativa de similar contenido sobre la materia. Con todo, el Tribunal Constitucional, en las sentencias roles n. $^{\circ} 1518$, c. 7 , y n..$^{\circ} 2682$, c. 13 , ha invocado el contenido de dicho proyecto de ley señalado: "Que si bien dicho proyecto no prosperó en definitiva, se admitirá que cristalizaba el derecho a defensa, de la manera en que secularmente se ha venido reconociendo a las personas a quienes se imputa la perpetración de un hecho sancionable en sede administrativa. Al paso de convenir que aquel texto guarda estrecha semejanza con el [...] artículo 35 de la Ley N. ${ }^{\circ} 19.880$ " (STC Rol n. ${ }^{\circ} 2682$, c. 14$)$.

42 Por ejemplo, la Ley 21.000, que crea la Comisión para el Mercado Financiero; la Ley 20.417, que crea el Ministerio, el Servicio de Evaluación Ambiental y la Superintendencia del Medio Ambiente; la Ley 20.529, que establece el Sistema Nacional de aseguramiento de la ca- 


\subsection{Las reacciones dogmáticas}

Tradicionalmente la materia fue analizada por la doctrina penal ${ }^{43}$. En términos generales, se buscaba distinguir las penas penales de las administrativas sobre la base de criterios sustantivos o cuantitativos, sin proporcionar una respuesta satisfactoria que permitiera precisar los límites que el legislador debiera observar en uno u otro caso.

Sin perjuicio de lo anterior, destacan los trabajos de Cury y Rodríguez, quienes intentaron dar coherencia interna a este sistema, estableciendo ciertos principios aplicables, aunque desde perspectivas diversas, la legal y la constitucional. Para el primero, el artículo 20 del Código Penal reconoce que las penas y las sanciones participan sustancialmente de la misma esencia y naturaleza ${ }^{44}$, siendo las sanciones necesarias dada la complejidad de la sociedad contemporánea, aunque, atendida su menor entidad, resulta inconveniente atribuirles las consecuencias penales y rodearlas de las mismas garantías. Sin embargo, es menester el establecimiento de ciertos límites a su ejercicio, como la observancia de los principios de legalidad constitucional, non bis in idem, culpabilidad, procedimiento simplificado, revisión judicial de la medida, tipificación mínima de la conducta y prescripción ${ }^{45}$. En tanto el segundo autor analiza el asunto desde la perspectiva constitucional, y considera que todos los principios fundamentales que rigen el ejercicio de la potestad punitiva criminal tienen aplicación también respecto de aquella conferida a la Administración, motivo por el cual las garantías y principios allí contemplados son aplicables a ambas medidas. El autor sustenta esta posición en diversas disposiciones constitucionales y legales ${ }^{46}$.

En el ámbito administrativo, uno de los primeros impulsores de la discusión fue Soto Kloss, quien estima que se trata de una potestad inconstitucional puesto que sancionar implica juzgar y la facultad jurisdiccional fue encargada por la Constitución en forma privativa al poder judicial y no a la Administración; por lo tanto, su ejercicio en manos de esta última la transforma en una comisión especial que atenta contra el derecho a un juez natural, vulnerando las garantías de un justo y racional procedimiento ${ }^{47}$. Por su parte, Aróstica,

lidad de la educación parvularia, básica y media y su fiscalización; la Ley 21.064, que reformó el Código de Aguas en materia de fiscalización y sanciones; entre otras.

43 P. ej., Labatut, G. Derecho penal. 9. ${ }^{a}$ ed. Santiago: Jurídica de Chile, 2000, I, 7 y 8; NovoA, E. Curso de derecho penal chileno. 3. ${ }^{\text {a }}$ ed., reimp. Santiago: Jurídica de Chile, 2010, I, 36-40; Etcheberry, A., Derecho penal.Parte general. 3. a ed. Santiago: Jurídica de Chile, 1998, II, 131-134; Cury, E. Derecho penal. Parte general. 7. a ed. Santiago: Universidad Católica de Chile, 2005, 100 ss.

44 Ibíd., 108.

45 Ibíd., 92.

46 RODRÍGUEZ. Bases para distinguir entre infracciones criminales y administrativas, cit., 152 ss.

47 Sото KLoss. Derecho administrativo penal, cit., 95-103. Recientemente, Sото KLoss, 
si bien comparte la doctrina anterior, en cuanto a que todo el poder sancionador debiera detentarlo por mandato constitucional el juez, reconoce que ello generaría una serie de problemas prácticos, por lo que estima necesario consentir un poder represivo a la Administración bajo ciertas reglas: i) que las potestades sancionadoras más rigurosos sean de competencia judicial; ii) que el poder represivo que se entregue a la Administración sea mínimo y susceptible de control judicial, y iii) que sobre ese poder se proyecten los principios jurídicos penales garantes de los derechos fundamentales, como el de legalidad de la infracción, el de legalidad de la sanción y el de non bis in idem ${ }^{48}$.

A estos autores siguieron otros tantos cuyas investigaciones no se limitaron a definir el fundamento constitucional de la potestad, sino que contribuyeron a determinar el marco normativo aplicable y el régimen de garantías y principios que la autoridad debería observar en su ejercicio, armonizando su contenido con los preceptos constitucionales y las garantías fundamentales. Existen diversos trabajos sistemáticos sobre la materia, los cuales pueden ser clasificados en: i) obras colectivas ${ }^{49}$; ii) obras individuales con referencia al sistema sancionador general ${ }^{50}$; iii) obras individuales con referencia a un sistema sancionador especial ${ }^{51}, \mathrm{y}$ iv) obras individuales con referencia al procedimiento administrativo sancionador ${ }^{52}$. A lo anterior se debe sumar la gran cantidad de publicaciones contenidas en diversas revistas científicas y otras sedes ${ }^{53}$.

E. Otra vez sobre la potestad sancionadora de la Administración. En Arancibia y Alarcón (coords.), Sanciones administrativas, cit., 39-52.

48 Aróstica. Algunos problemas del derecho administrativo penal, cit., 77 y 78.

49 P. ej., Soто Kloss, E. (coord.). Conferencias Santo Tomás de Aquino. Sanciones administrativas y derechos fundamentales. Santiago: Universidad Santo Tomás, 2005, y ARANCIBIA y Alarcón (coords.). Sanciones administrativas, cit.

50 CORDERo. Derecho administrativo sancionador, cit., en el cual se presenta una visión global del fenómeno de las sanciones administrativas en Chile conforme a los desarrollos de la doctrina, la jurisprudencia y la legislación vigentes. Véase asimismo ENTEICHE, N. Las sanciones administrativas. El problema de la proporcionalidad. Valencia: Tirant Lo Blanch, 2017, y Celis, G. Derecho administrativo sancionador. Santiago: El Jurista, 2018.

51 Salinas, C. Derecho administrativo sancionador. El régimen sancionador eléctrico en Chile. Santiago: Thomson Reuters y Puntolex, 2010.

52 Osorio, C. Manual de procedimiento administrativo sancionador. Parte general. Santiago: Thomson Reuters y La Ley, 2016, 641, y DE QuezadA, F. Procedimiento administrativo sancionador en la Ley $N .^{\circ}$ 19.880. Santiago: Librotecnia, 2017.

53 P. ej., Vergara, A. Esquema de los principios del derecho administrativo sancionador. En Revista de Derecho, Coquimbo. Año 11, N. ${ }^{\circ}$ 2, 2004, 137-147; Román, C. Derecho administrativo sancionador: “¿Ser o no ser? He ahí el dilema”. En PANTOJa, R. (ed.), Derecho administrativo. 120 años de cátedra. Santiago: Jurídica de Chile, 2008, 107-141; NAVARro, E. Notas sobre la potestad sancionatoria de la autoridad administrativa y principio de legalidad. En Revista de Derecho Público. N. ${ }^{\circ}$ 67, 2005, 118-128; Fernández, M. Á. Potestad sancionadora de la Administración y ley penal en blanco: caso de las eléctricas ante el Tribunal Constitucional. En Anuario de Doctrina y Jurisprudencia: sentencias destacadas 2006. Santiago: Instituto 


\subsection{Los pronunciamientos de la jurisprudencia judicial en torno al poder sancionador de la Administración}

Sin perjuicio de algunos pronunciamientos históricos respecto de la potestad sancionadora de los municipios ${ }^{54}$, de la Administración central ${ }^{55}$ y de la aplicación del principio de prescripción en materia tributaria ${ }^{56}$, las reacciones más importantes de la jurisprudencia datan de la segunda mitad de los años sesenta. Los tribunales, con el objeto de aplicar ciertas garantías mínimas a este tipo de sanciones, sostuvieron que la expresión "condenado", en aquel

Libertad y Desarrollo, 2007, 173-205; BoETTIGER, C. El derecho administrativo sancionador en la jurisprudencia del Tribunal Constitucional. En Actualidad Jurídica. N. . 20, 2009, 577-596; BERMúdez, J. Fundamentos y límites de la potestad sancionadora administrativa en materia ambiental. En Revista de Derecho, Valparaíso. N. . 40, 2013, 421-447; HuEPE, F. El problema de la discrecionalidad en la potestad sancionadora de la Administración. Su control a través del principio de razonabilidad. En ArANCIBIA y Alarcón (coords.), Sanciones administrativas, cit., 168-186; LondoÑo, F. Tipicidad y legalidad en el derecho administrativo sancionatorio. En Revista de Derecho, Valdivia. Vol. 27, n. ${ }^{\circ}$ 2, 2014, 147-167; Guiloff, M. y Soto, P. Sanciones administrativas, discrecionalidad y revisión judicial: una mirada desde la regulación responsiva. En Ferrada, J. C.; Bermúdez, J. y Pinilla, F. (coords.), La nueva justicia ambiental. Santiago: Thomson Reuters y La Ley, 2015, 101-124; Letelier, R. La ejecutoriedad de las sanciones administrativas. A propósito de la sentencia de la Corte Suprema en el caso Mackenna. En Anuario de Derecho Público, 2015, 316-332; Gómez, R. F. El non bis in idem en el derecho administrativo sancionador. Revisión de sus alcances en la jurisprudencia administrativa. En Revista de Derecho, Valparaíso, 2017, 101-138; entre otras publicaciones.

54 Véanse: i) Sentencia de CS, del 13 de marzo de 1897, Gaceta de los Tribunales, 1897, fallo n. $.^{\circ} 74,41-43$ (c. $3 .^{\circ}$ ), y ii) Sentencia de la Corte de Apelaciones de Concepción, del 30 de agosto de 1897, Gaceta de los Tribunales, 1897, t. II, n. ${ }^{\circ} 3.520,929-931$, (cc. $7 .^{\circ}$ y $8 .^{\circ}$ del fallo de primera instancia).

55 Véase sentencia de la Corte de Apelaciones de La Serena, del 6 de abril de 1923, en Gaceta de los Tribunales, $1923,2 .^{\circ}$ semestre, $n .^{\circ} 80,416$, fallo en el cual se expresa que la autoridad marítima no es competente para aplicar sanciones por infracciones a las ordenanzas de policía marítima, sino que lo es la justicia ordinaria, conforme a lo dispuesto en los artículos 99 (108) de la Constitución y $1 .^{\circ}$ y $5 .^{\circ}$ de la Ley de Organización y Atribuciones de los Tribunales de Justicia. Posteriormente, la Corte señaló que las garantías penales contempladas en la Constitución no eran aplicables a las sanciones administrativas, puesto que cuando la autoridad aplicaba sanciones administrativas lo hacía en el ejercicio de una potestad de la misma índole, la que no tenía ninguna relación con un enjuiciamiento criminal: véase, en este sentido, la sentencia del 27 de diciembre de 1955, en la que la Corte resolvió el recurso de inaplicabilidad interpuesto por José Etcheberry a propósito de la obligación de consignar el importe de multa aplicada por el Director General de Impuestos Internos como requisito de admisibilidad para impugnarla (solve et repete).

56 La Corte Suprema, en una causa en la cual se solicitaba la prescripción de una sanción aplicada por el Director de Impuestos Internos conforme a los plazos penales, sostuvo que la "potestad correctiva", que diversas leyes orgánicas conferían a los jefes superiores de los servicios, era una jurisdicción encaminada al castigo de los particulares responsables de las infracciones que dichas leyes contemplaban, siendo estas últimas diferentes de los delitos y faltas sometidas a las reglas del Código Penal. Así, las autoridades podrían juzgar y resolver en única instancia, aplicando las multas establecidas en esas leyes, sin perjuicio de la posterior reclamación judicial de la medida. Para la Corte, estas sanciones no participaban de los especiales efectos y caracteres de las infracciones y penas contempladas en el Código Penal: así en sentencia del 9 de octubre de 1939, Revista de Derecho, t. XXXVII, segunda parte, sección primera, 330 ss. 
entonces contenida en el artículo 11 de la Constitución de 1925 -actual art. 19 n. ${ }^{\circ} 3-$, no solo era comprensiva de las sanciones penales, sino de todas las sanciones en un sentido amplio ${ }^{57}$. De esta manera se indicó que las sanciones pecuniarias contempladas en leyes civiles, procesales, tributarias, aduaneras, sanitarias, municipales, administrativas, laborales, etc. no perdían su carácter de penas por la circunstancia de no haber sido establecidas en leyes exclusivamente penales ni por el hecho de que su aplicación correspondiera a autoridades, funcionarios u organismos distintos a los tribunales ordinarios o especiales, por lo cual les eran aplicables ciertos principios y garantías penales, como la irretroactividad ${ }^{58}$.

En los años siguientes, la jurisprudencia judicial irá dejando en evidencia la necesidad de que la Administración racionalice el ejercicio de sus poderes represivos. Dicha exigencia comienza a ser controlada fundamentalmente por dos vías: a) la utilización de las técnicas propias del derecho administrativo, en concreto, con la revisión de la legalidad del acto administrativo (control de motivos de hecho, calificación jurídica, fundamentación del acto, entre otros), y b) la aplicación de ciertos principios sustantivos y procedimentales, en concreto, aquellos propios del derecho penal constitucionalizado (v.gr., irretroactividad, prescripción).

\subsection{El punto de inflexión impuesto por la sentencia Rol n..$^{\circ} 244$ del Tribunal Constitucional}

Uno de los hitos más relevantes en este proceso de racionalización de la potestad administrativa sancionadora provino de la jurisprudencia constitucional. En efecto, en 1996 el Tribunal Constitucional, a través de la sentencia Rol n. ${ }^{\circ}$ $244^{[59]}$, conociendo del control preventivo de constitucionalidad del proyecto de Ley de Caza, incorporó en el ordenamiento jurídico la doctrina del ius puniendi propio del Estado, cuyo origen se encuentra en la jurisprudencia judicial y constitucional española ${ }^{60}$ conforme a la cual, por regla general, los principios constitucionales del orden penal son aplicables al derecho administrativo sancionador. Este pronunciamiento es de gran relevancia, por cuanto:

57 El artículo 11 consagraba el principio de irretroactividad.

58 "Alessandri Rodríguez, Arturo" (27 de diciembre de 1965), en Revista de Derecho y Jurisprudencia, t. 62 (1965), segunda parte, sección tercera, 114-119; "Yarur Asfura, Daniel" (31 de marzo de 1966), en Revista de Derecho y Jurisprudencia, t. 63 (1966), segunda parte, sección primera, 94-110; "Valdés Freire, Luis" (5 de julio de 1966), en Revista de Derecho y Jurisprudencia, t. 63 (1966), segunda parte, sección tercera, 88-91; "Banco de Crédito e Inversiones" (12 de julio de 1966), en Revista de Derecho y Jurisprudencia, t. 63 (1966), segunda parte, sección tercera, 93-95; "Bolumburu Pin, Ezequiel" (13 de agosto de 1966), en Revista de Derecho y Jurisprudencia, t. 63 (1966), segunda parte, sección tercera, 105-109; entre otros.

59 Considerandos $9 .^{\circ}$ y siguientes.

60 Véanse la sentencia 3776/1972, del 9 de febrero, del Tribunal Supremo español y la sentencia 18/1981, del 8 de junio, del Tribunal Constitucional español. 
i) Establece una importante prevención al legislador. El fallo representa un categórico mensaje al legislador al señalar que tanto los artículos de la Ley de Caza, que son objeto de control ${ }^{61}$, como las sucesivas regulaciones, deben observar en forma estricta el mandato constitucional impuesto por los principios de legalidad y de tipicidad, conforme a los cuales corresponde a la ley y solo a ella establecer al menos el núcleo esencial de las conductas que se sancionan, materia que es de exclusiva y excluyente reserva legal, en términos tales que no procede respecto de ella ni siquiera la delegación de facultades legislativas al Presidente de la República, en conformidad con el artículo 61 , inciso $2 .^{\circ}$, de la Constitución (c. $\left.12 .^{\circ}\right) \mathrm{y}$,

ii) Establece un primer bloque de principios mínimos o de base. Aunque hoy en día esto es cuestionado por la doctrina ${ }^{62}$, la sentencia dispuso un primer nivel de lo que sería el proceso de construcción dogmática del régimen administrativo sancionador nacional. Con este fallo se integran a este "precario" sistema represivo los principios constitucionales del orden penal, haciendo una especial referencia a los principios de legalidad y tipicidad ${ }^{63}$. El primero se cumplirá con la previsión de las infracciones y de las sanciones en la ley, mientras que el segundo se cumplirá con la precisa definición de la conducta que la ley considera reprochable. Asimismo, el Tribunal considera que estos dos principios ayudarán a garantizar la seguridad jurídica y a concretar la exigencia de una ley previa y cierta $\left(\right.$ c. $\left.10 .^{\circ}\right)$.

De esta manera, el fallo reconoce expresamente el marco de principios que deberán ser considerados en la atribución de cualquier manifestación de la potestad punitiva. Se trata de una "base mínima" cuyo objeto fue proporcionar

61 El Tribunal declaró que concretamente la frase "o a su reglamento", contemplada en el inciso segundo del artículo 37 del proyecto sometido a su control, era inconstitucional dado que atribuía competencia al Servicio Agrícola y Ganadero para conocer y sancionar administrativamente no solo las contravenciones a dicha norma, sino también a su reglamento, lo cual resultaba contrario a la Constitución al vulnerar la reserva legal (cc. $14 .^{\circ}$ y $\left.15 .^{\circ}\right)$. Dicho estaba redactado en los siguientes términos: "Artículo 37. El conocimiento y castigo de los delitos a que se refieren los artículos 30 y 31 corresponderá al juez del crimen competente.

"Asimismo, el Servicio Agrícola y Ganadero será competente para conocer y sancionar administrativamente las contravenciones a esta ley o a su reglamento, en conformidad a lo dispuesto en la ley n. ${ }^{\circ} 18.755 "$ ".

62 Este fallo fue calificado por Letelier como "excesivo" puesto que el propio derecho penal tolera que diversas figuras penales no estén descritas plenamente en la ley, y también porque gran parte de las sanciones administrativas proceden por infracciones a normas infralegales. Es por ello que el autor en cita estima que seguir la doctrina de la sentencia del Tribunal Constitucional Rol n. ${ }^{\text {o } 244-1996}$ implicaría declarar inconstitucionales un alto porcentaje de las sanciones administrativas actualmente vigentes. Véase Letelier, R. Garantías penales y sanciones administrativas. En Política Criminal. Vol. 12, n. ${ }^{\circ}$ 24, 2017, art. 1, 626.

$63 \mathrm{Al}$ respecto, Soto Kloss señala que "esta pretendida 'purificación' no logra sanear en modo alguno su contrariedad [de la potestad] con la Constitución, porque aun cuando se sea muy estricto en aplicar esos principios[,] lo que jamás podrá ser saneado es aquello que jamás tendrá la Administración sancionadora, como es “independencia e imparcialidad"'. Sото KLoss. Otra vez sobre la potestad sancionadora de la Administración, cit., 39. 
cierta racionalidad al ejercicio de la potestad, exigiendo que su ejercicio sea más acorde con los principios y garantías constitucionales vigentes.

Esta doctrina fue reiterada en diversos fallos posteriores del Tribunal Constitucional ${ }^{64}$, llegando inclusive a hacerse extensiva al orden procedimental ${ }^{65}$. Asimismo, el fortalecimiento de esta interpretación se fue consolidando con la progresiva adhesión que mostraron tanto la Contraloría General de la República ${ }^{66}$ como los tribunales de justicia ${ }^{67}$ y la doctrina administrativa ${ }^{68}$.

iii) Se le atribuye una denominación propia. Este fallo utiliza por primera vez la denominación "derecho administrativo sancionador" para referirse a la potestad represiva de la Administración, lo que por la doctrina fue interpretado como un reconocimiento implícito a la autonomía de la disciplina ${ }^{69}$.

Este pronunciamiento marcó un punto de inflexión en materia administrativa sancionadora, al dejar en evidencia la necesidad de racionalizar el ejercicio

64 Doctrina reiterada posteriormente en las sentencias roles n. ${ }^{\circ} 437-2005,479-2006$, 480-2006, 694-2006, 695-2006, 747-2007, 725-2007, 1.183-2008, 1.184-2008, 1.203-2008, 1.205-2008, 1.221-2008, 1.223-2008, 1.229-2008, 1.233-2008, 1.245-2008, 1.413-2009, 1.518 2009, 1.568-2009, 1.872-2010, 2.264-2012, 2.346-2012, 2.381-2012, 2.626-2014, 2.666-2014, 2.682-2014, 2.722-2014, 2.729-2014 y 2.831-2015.

65 En fallos posteriores el Tribunal se pronunció sobre la necesidad de que, al momento de establecer disposiciones sancionatorias, el legislador contemple un procedimiento que permita al afectado una adecuada defensa de sus derechos, en sede administrativa, en forma previa a la imposición de las sanciones que en cada caso se establecen; véanse, p. ej., las sentencias del Tribunal Constitucional roles n. $.^{\circ} 376-2003$ (c. $\left.34 .^{\circ}\right) ;$ n. ${ }^{\circ} 388-2003$, en particular cuando precisa que solo al legislador le corresponde establecer siempre las garantías de un racional y justo procedimiento, y no a la Administración vía reglamentaria (c. 26. ${ }^{\circ}$ ); y n. ${ }^{\circ} 389-2003$ (c. 33. ${ }^{\circ}$ ), entre otros.

$66 \mathrm{Al}$ respecto, véase el Dictamen n. ${ }^{\circ} 14.571$ de 2005, en el cual se recogió la doctrina del Tribunal Constitucional. Con todo, para la Contraloría los principios penales son extrapolables tanto a la potestad sancionadora como a la disciplinaria.

67 La Corte Suprema comparte la doctrina que sobre la materia han sostenido la jurisprudencia constitucional y la administrativa, pero considera los aspectos sustantivos que separan a los delitos de las infracciones administrativas, para matizar en la proyección de los principios y normas del orden penal al ámbito de las sanciones administrativas. Véase CORDERo. Derecho administrativo sancionador, cit., 60 ss.

68 P. ej., Vergara señala que esta sentencia reconoce que, aunque exista dualidad de sistemas represivos del Estado, los principios conocidos generalmente como del derecho penal deben ser considerados como principios generales del derecho sancionador, lo cual incluye la esfera sancionatoria administrativa. Véase Vergara. Esquema de los principios del derecho administrativo sancionador, cit., 140. A su turno, Navarro Beltrán, a casi diez años del fallo y revisando pronunciamientos sustentados en él, indica que el Tribunal Constitucional ha sido bastante claro en confirmar la doctrina en cuanto a que las disposiciones constitucionales relativas a las garantías judiciales penales resultan plenamente aplicables en materia administrativa. Véase NAVARRo. Notas sobre la potestad sancionatoria de la autoridad administrativa y principio de legalidad, cit., 121. Otros autores, por su parte, hacen un llamado a trabajar en la precisión de los matices a los principios para darles una eficacia real. Véase, p. ej., CÁrCAMO, A. La constitucionalidad y la necesidad del derecho administrativo sancionador correctivo en el complejo escenario económico moderno. En Gaceta Jurídica. Vol. 363, 2010, 7-18.

69 Román. Derecho administrativo sancionador, cit., 107-141. 
de la potestad sancionadora ajustando su aplicación a los principios y garantías fundamentales. En efecto, en aquel momento, el Tribunal Constitucional estimó que los principios constitucionales del orden penal resultaban ser los más idóneos para proteger y garantizar los derechos de los sujetos infractores.

Sin embargo, con el transcurso del tiempo quedó en evidencia que la aplicación de los principios y garantías penales no se corresponde con la lógica y finalidad que subyace al ejercicio de la potestad sancionadora, en donde el objetivo principal no es imponer una sanción sino garantizar a través de ella una finalidad pública de interés general, siendo necesario tomar cierta distancia de las reglas penales y recurrir a las instituciones propias del régimen jurídico público ${ }^{70}$.

\subsection{Análisis de los recientes cuestionamientos a la constitucionalidad de la potestad sancionadora: los casos Código de Aguas y Servicio Nacional del Consumidor (SERNAC)}

En fallos recientes, el Tribunal Constitucional ha cuestionado la constitucionalidad de la potestad sancionadora de la Administración, ello a propósito del control previo de legalidad de los proyectos de ley sobre reforma al Código de Aguas y al Servicio Nacional de Protección al Consumidor, en materia de sanciones ${ }^{71}$. En el primero de los pronunciamientos se establece un principio de no regresión, por cuanto, si la ley ha dispuesto que sea el juez quien conozca de una infracción y aplique la sanción respectiva, dicha competencia no podría ser posteriormente modificada por el legislador ${ }^{72}$. En el segundo de ellos, el Tribunal cuestionó las diversas potestades que la ley le atribuía al SERNAC, a saber, la interpretativa, la normativa y la sancio-

70 En la sentencia Rol n. ${ }^{\circ}$ 1079-2014, la Corte Suprema señaló que de "la identidad ontológica entre la sanción penal y [la] administrativa no se sigue la correlativa identidad de régimen jurídico, pues ello implicaría aceptar todas las consecuencias jurídicas del primero en el segundo". En tal sentido, sostuvo que para la aplicación de una sanción "no corresponde aplicar, de manera categórica y automática, el estatuto jurídico de las sanciones penales, sino que cuando se pretenda hacer aplicación de dicho estatuto, se debe[n] tener en cuenta aquellos aspectos del derecho administrativo sancionador que le confieren a esta rama una fisonomía propia y que justifican su regulación autónoma en relación con el derecho penal". En este punto, previo a una aplicación del régimen jurídico penal, cabe atender las normas correspondientes al derecho común administrativo, conformado por la Ley 18.575, Ley de Bases Generales de la Administración del Estado, la Ley 19.880, sobre procedimiento administrativo, la Ley 20.285, sobre acceso a la información pública, la Ley 10.336, Ley Orgánica de la Contraloría General de la República, y la Ley 18.834, estatuto administrativo, entre otras disposiciones que forman parte de la legislación administrativa general.

71 Sentencias roles n. ${ }^{\circ} 3958-2017$ y n. ${ }^{\circ} 4012-2017$

72 Véase el comentario de José Miguel Valdivia. "Constitucionalidad de las sanciones administrativas en materia de aguas". [En línea]. Disponible en: http://www.derecho.uchile. $\mathrm{cl} /$ comunicaciones/columnas-de-opinion/140485/constitucionalidad-de-las-sancionesadministrativasbrjose-valdivia [Consultado el 13 de enero de 2019]. 
nadora, por cuanto la reunión de todas ellas implicaría que, tratándose de la aplicación de sanciones, el servicio sería juez y parte, lo que vulneraría el derecho a ser juzgado por un tribunal independiente e imparcial y conforme a las garantías de un debido proceso (art. 19 n. ${ }^{\circ} 3$ de la Carta Fundamental).

Ahora bien, aun cuando en la última de las sentencias mencionadas se precisó que dicha decisión no se extiende necesariamente a otros casos de organismos administrativos con potestades sancionadoras, pues lo allí cuestionado es que "el mismo servicio estatal llamado a proteger a una de las partes lucrativamente interesadas, los consumidores, sea instituido como árbitro supremo, para luego dirimir los contenciosos e impugnaciones que enderecen contra sus proveedores" 73 , se trata de una jurisprudencia que cuestiona los fundamentos constitucionales de la potestad sancionadora, los cuales, hasta la fecha, son mayoritariamente aceptados por la jurisprudencia y la doctrina de diverso orden. Por tanto, será preciso observar la evolución de esta doctrina del Tribunal Constitucional y las consecuencias que pueda tener en las futuras disposiciones sancionadoras.

\section{BALANCE FINAL}

De lo expuesto, se puede afirmar que en Chile las sanciones administrativas serían una consecuencia del ejercicio de las potestades de policía. En efecto, al igual que en otros sistemas jurídicos, la policía se mantuvo como la más típica e inmediata manifestación de la supremacía administrativa -otrora regia-, la cual, invocando razones de orden público, podía intervenir en diversas esferas de la libertad y la propiedad de las personas.

Así, durante el siglo XIX el poder represivo en Chile fue heredero de las viejas disposiciones de policía de orden y seguridad pública de la época de la Colonia, las que fueron toleradas al margen de los estrictos preceptos constitucionales en materia de medidas punitivas.

Esta situación se mantuvo durante buena parte del siglo xx, hasta que la jurisprudencia y la doctrina comenzaron a encauzar su ejercicio por la vía de los principios clásicos del orden penal, con sujeción a ciertos matices, alcanzando su consolidación con la sentencia del Tribunal Constitucional en la causa Rol n. ${ }^{\circ} 244$ de 1996, en la cual por primera vez se sostiene que los principios del orden penal contemplados en la Constitución se deben aplicar, por regla general, a las sanciones administrativas.

Lo anterior tiene particular importancia en el caso del estricto principio de legalidad que domina en el ámbito penal. En efecto, dicho principio no recibe un tratamiento similar en el ámbito administrativo, pues en sede penal la gravedad de las medidas punitivas y su fuerte incidencia en la esfera de las personas exigen mayores garantías en la configuración de los ilícitos, en

73 STC. Rol n. ${ }^{\circ} 4012-2017$, c. $39 .^{\circ}$. 
la determinación de las penas y en el proceso judicial. Y, por otra parte, en el ámbito administrativo se admite un mayor margen de discrecionalidad, atendiendo a sus fines y medios, aunque sujeto a una serie de límites y controles propios del orden constitucional, que lo alejan del régimen de policía propio del Antiguo Régimen.

Asimismo, si bien en dicho fallo se validó la constitucionalidad de la potestad, fue necesario dar lugar a la determinación, por una parte, del régimen jurídico de las sanciones, y, por la otra, de las garantías y los principios aplicables al ejercicio de dicha potestad. Es por ello que el legislador, en las posteriores disposiciones sancionadoras sectoriales, fue configurando con un mayor detalle las conductas constitutivas de infracciones, su clasificación, los tipos de sanciones y los criterios que deben ser utilizados para su determinación, lo cual refleja un mayor grado de correspondencia con los principios constitucionales y con las garantías y derechos fundamentales de los particulares.

Finalmente, los recientes cuestionamientos que el Tribunal Constitucional ha realizado respecto de la potestad sancionadora de la Administración hacen que sea necesario evaluar las consecuencias que dichos pronunciamientos puedan tener en las futuras disposiciones sancionadoras.

\section{REFERENCIAS}

Anguita, R. Leyes promulgadas en Chile. Desde 1801 hasta el 1. ${ }^{\circ}$ de junio de 1913. Santiago: Imprenta Litografía, 1913.

Arancibia, J. y Alarcón, P. (coords.). Sanciones administrativas. Santiago: Thomson Reuters y La Ley, 2014.

Araya, M. El solve et repete frente al derecho administrativo sancionador. Un examen de legitimidad. En Revista de Derecho. N. . 3, 2013, 95-126.

Aróstica, I. Algunos problemas del derecho administrativo penal. En Revista de Derecho, Universidad de Concepción. N.182, 1987, 71-81.

Balmaceda, G. Manual de derecho penal. Parte general. Santiago: Librotecnia, 2014.

BERMÚdeZ, J. Fundamentos y límites de la potestad sancionadora administrativa en materia ambiental. En Revista de Derecho, Valparaíso. N. o 40, 2013, 421-447.

BERMÚdEz, J. Reglas para la imposición de las sanciones administrativas en materia ambiental. En Arancibia, J. y Alarcón, P. (coords.), Sanciones administrativas. Santiago: Thomson Reuters y La Ley, 2014, 609-632.

BocksANG, G. El "secuestro de bienes" como primera sanción administrativa del Estado de Chile. En Arancibia, J. y Alarcón, P. (coords.), Sanciones administrativas. Santiago: Thomson Reuters y La Ley, 2014, 633-649. 
Boettiger, C. El derecho administrativo sancionador en la jurisprudencia del Tribunal Constitucional. En Actualidad Jurídica n. ${ }^{\circ}$ 20, 2009, 577-596.

CÁrcamo, A. La constitucionalidad y la necesidad del derecho administrativo sancionador correctivo en el complejo escenario económico moderno. En Gaceta Jurídica. Vol. 363, 2010, 7-18.

Celis, G. Derecho administrativo sancionador. Santiago: El Jurista, 2018.

Cordero, E. Derecho administrativo sancionador. Bases y principios en el derecho chileno. Santiago: Legal Publishing, Thomson Reuters y La Ley, 2014.

Cordero, L. Lecciones de derecho administrativo. Santiago: Legal Publishing, 2015.

CURY, E. Algunas reflexiones sobre la relación entre penas penales y administrativas. En Boletín de Investigaciones, . $^{\circ} 44$ y 45, 1979/1980, 86-94.

Cury, E. Derecho penal.Parte general. 7. ed. Santiago: Universidad Católica de Chile, 2005.

ENTEICHE, N. Las sanciones administrativas. El problema de la proporcionalidad. Valencia: Tirant Lo Blanch, 2017.

Etcheberry, A. Derecho penal. Parte general. 3. a ed. Santiago: Jurídica de Chile, 1998, iI.

Fernández, M. Á. Potestad sancionadora de la Administración y ley penal en blanco: caso de las eléctricas ante el Tribunal Constitucional. En Anuario de Doctrina y Jurisprudencia: sentencias destacadas 2006. Santiago: Instituto Libertad y Desarrollo, 2007, 173-205.

Flores, J. C. Función fiscalizadora y potestad sancionadora de la Administración. En Arancibia, J. y Alarcón, P. (coords.), Sanciones administrativas. Santiago: Thomson Reuters y La Ley, 2014, 263-281.

García de Enterría, E. y Fernández, T. R. Curso de derecho administrativo. 10. a ed. Madrid: Thomson Civitas, 2006, II.

García de EnTERría, E. El problema jurídico de las sanciones administrativas. En Revista Española de Derecho Administrativo. N. ${ }^{\circ}$ 10, 1976, 399-430.

GARrido, F. Los medios de la policía y la teoría de las sanciones administrativas. En Revista de Administración Pública. ‥ $28,1958,11-50$.

Garrido, F.; Palomar, A. y Losada, H. Tratado de derecho administrativo. Parte general. Conclusión. Vol. II, 12. ed. Madrid: Tecnos, 2006.

Garrido, M. Derecho penal. Parte general. 3. a ed. Santiago: Jurídica de Chile, 2002, I.

Gómez, R. F. El non bis in ídem en el derecho administrativo sancionador. Revisión de sus alcances en la jurisprudencia administrativa. En Revista de Derecho, Valparaíso, 2017, 101-113.

Guiloff, M. у Soto, P. Sanciones administrativas, discrecionalidad y revisión judicial: una mirada desde la regulación responsiva. En Ferrada, J. C., Bermúdez, J. y Pini- 
LLA, F. (coords.), La nueva justicia ambiental. Santiago: Thomson Reuters y La Ley, 2015, 101-124.

Guzmán, A. Historia de la codificación civil en Iberoamérica. Navarra: Thomson Aranzadi, 2006.

Huepe, F. El problema de la discrecionalidad en la potestad sancionadora de la Administración. Su control a través del principio de razonabilidad. En Arancibia, J. y Alarcón, P. (coords.), Sanciones administrativas. Santiago: Thomson Reuters y La Ley, 2014, 168-186.

Huneeus, J. La Constitución ante el Congreso. Santiago: Cervantes, 1891. Vol. 3, II.

Labatut, G. Derecho penal. 9. a ed. Santiago: Jurídica de Chile, 2000, I.

Letelier, R. Garantías penales y sanciones administrativas. En Política Criminal. Vol. 12, n. $^{\circ} 24,2017$, art. 1, 622-689.

Letelier, R. La ejecutoriedad de las sanciones administrativas. A propósito de la sentencia de la Corte Suprema en el caso Mackenna. En Anuario de Derecho Público. 2015, 316-332.

Letelier, V. Génesis del Estado y de sus instituciones fundamentales. Introducción al estudio del derecho público. Buenos Aires: Cabaut, 1917.

Londoño, F. Tipicidad y legalidad en el derecho administrativo sancionatorio. En Revista de Derecho, Valdivia. Vol. 27, n. ${ }^{\circ}$ 2, 2014, 147-167.

Navarro, E. Notas sobre la potestad sancionatoria de la autoridad administrativa y principio de legalidad. En Revista de Derecho Público. N. ${ }^{\circ}$ 67, 2005, 118-128.

Nieto, A. Derecho administrativo sancionador. 4. a ed. Madrid: Tecnos, 2005.

Nieto, A. Derecho administrativo sancionador. 5. a ed. Madrid: Tecnos, 2012.

NovoA, E. Curso de derecho penal chileno. 3. a ed. Santiago: Jurídica de Chile, 2010, I.

Osorio, C. Manual de procedimiento administrativo sancionador. Parte general. Santiago: Thomson Reuters, La Ley, 2016.

Quezada, F. Procedimiento administrativo sancionador en la Ley $N .^{\circ} 19.880$. Santiago: Librotecnia, 2017.

RAJEvic, E. La sinuosa reserva legal de la potestad sancionadora y los privados que ejercen funciones públicas: navegando entre relaciones de sujeción especial y la contractualización. En Arancibia, J. y Alarcón, P. (coords.), Sanciones administrativas. Santiago: Thomson Reuters y La Ley, 2014, 89-105.

Rodríguez, L. Bases para distinguir entre infracciones criminales y administrativas. En Revista de Derecho, Valparaíso. Vol. 11, 1987, 117-164.

RoJas, M. y León, M. Control social y construcción de hegemonía en la ciudad de Concepción (Chile), 1860-1900. En Anuario de Estudios Americanos, Sevilla. 70, 2 2013, 641-671. 
Román Cordero, C. Derecho administrativo sancionador: “¿Ser o no ser? He ahí el dilema”. En Pantoja, R. (ed.), Derecho administrativo. 120 años de cátedra. Santiago: Jurídica de Chile, 2008, 107-141.

Román, C. El castigo en el derecho administrativo. En Revista de Derecho y Humanidades. Vol. 1, n. ${ }^{\circ} 16,2010,155-171$.

Salinas, C. Derecho administrativo sancionador. El régimen sancionador eléctrico en Chile. Santiago: Thomson Reuters y Puntolex, 2010.

Santamaría, J. A. Principios de derecho administrativo general. Vol. il, 4. a ed. Madrid: Iustel, 2016.

Santamaría, J. A. y Parejo, L. Derecho administrativo. La jurisprudencia del Tribunal Supremo. Madrid: Centro de Estudios Ramón Areces, 1992.

Soto Kloss, E. (coord.). Conferencias Santo Tomás de Aquino. Sanciones administrativas $y$ derechos fundamentales. Santiago: Universidad Santo Tomás, 2005.

Sото KLoss, E. Derecho administrativo penal. Notas para el estudio de la potestad sancionadora de la Administración. En Boletín de Investigaciones. ‥ 44-45, 1979/1980, 95-103.

Soto Kloss, E. Otra vez sobre la potestad sancionadora de la Administración. En ARAnCIBia, J. y Alarcón, P. (coords.), Sanciones administrativas. Santiago: Thomson Reuters y La Ley, 2014, 39-52.

Soto Kloss, E. Solve et repete. Notas sobre un resabio absolutista en el Estado constitucional del derecho. En Ius Publicum. Vol. 4, n. ${ }^{\circ}$ 6, 2001, 79-100.

Vergara, A. Esquema de los principios del derecho administrativo sancionador. En Revista de Derecho, Coquimbo. Año 11, n. 2, 2004, 137-147.

VIÑUela, M. Algunas reflexiones en torno al derecho administrativo sancionador: la aplicación residual de sanciones administrativas y el principio de legalidad de las penas. En Arancibia, J. y Alarcón, P. (coords.), Sanciones administrativas. Santiago: Thomson Reuters y La Ley, 2014, 107-125. 